\title{
PENDEKATAN WHOLE LANGUAGE MELALUI MULTI MEDIA DALAM PENINGKATAN KETERAMPILANPEMBELAJARAN BAHASA ARAB BAGI MAHASISWA PRODI PENDIDIKAN BAHASA ARAB, FAKULTAS TARBIYAH DAN KEGURUAN UIN SUNAN AMPEL SURABAYA
}

\author{
Muflihah \\ UIN Sunan Ampel Surabaya \\ muflihah@uinsby.ac.id
}

\begin{abstract}
An important problem faced by lecturers in learning Arabic is technology-based learning or through multimedia. Therefore, the author examines this through research to find out a number of issues, namely: 1) How to design learning with a whole language approach through Multi Media in improving Arabic language skills for Arabic education department at Tarbiyah and Teacher Training Faculty of UIN Sunan Ampel Surabaya? 2) How is the implementation of learning with the whole language approach through Multi Media in improving Arabic language skills for students of Arabic education department at Tarbiyah and Teacher Training Faculty of UIN Sunan Ampel Surabaya? The results of this study are that the implementation of learning with the whole language approach through multimedia is in class D as an experimental class, the researcher also implements learning by not using the whole language approach through Multi Media as a comparison class that is in class $B$ and based on the results of calculations performed using applications Minitab 16 can be seen that the value of the t-test from the pre-test and posttest table in the experimental class or class D is 10.99 and the value of the $t$ count from the class B pre-test and post-test table is 5.75 .
\end{abstract}

Keywords: Whole Language Approach; Multi Media; Arabic Language

\begin{abstract}
Abstrak: Masalah penting yang dihadapi dosen dalam pembelajaran Bahasa Arab adalah pembelajaran berbasis teknologi atau melalui multimedia. Oleh karena itu, penulis mengkaji masalah tersebut melalui penelitian untuk mengetahui beberapa persoalan, yaitu :1) Bagaimana desain pembelajaran dengan pendekatan whole language melalui Multi Media dalam peningkatan keterampilan Bahasa Arab bagi mahasiswa prodi pendidikan Bahasa Arab, Fakultas Tarbiyah dan Keguruan, UIN Sunan Ampel Surabaya? 2) Bagaimana implementasi pembelajaran dengan pendekatan whole language melalui Multi Media dalam peningkatan keterampilan Bahasa Arab bagi mahasiswa prodi pendidikan Bahasa Arab Fakultas Tarbiyah dan Keguruan UIN Sunan Ampel Surabaya ? Hasil penelitian ini adalah bahwa implementasinya pembelajaran dengan pendekatan whole language melalui multimedia adalah pada kelas $\mathrm{D}$ sebagai kelas eksperimen, peneliti juga mengimplementasikan pembelajaran dengan tidak mengunakan pendekatan whole language melalui Multi Media sebagai kelas pembanding yaitu pada kelas B dan berdasarkan hasil perhitungan yang dilakukan dengan menggunakan aplikasi Minitab 16 dapat diketahui bahwa besarnya nilai t-hitung dari tabel pre-test dan post-test pada kelas eksperimen atau kelas D adalah sebesar 10.99 dan besarnya nilai t-hitung dari tabel pre-test dan post-test kelas B adalah sebesar 5.75.
\end{abstract}

Kata kunci: Pendekatan Whole Language; Multi Media; Bahasa Arab 


\section{PENDAHULUAN}

Penguasaan Bahasa Arab tidak dapat dipisahkan dari empat keterampilan berbahasa yaitu keterampilan menyimak, berbicara, membaca, dan keterampilan menulis, pembelajaran bahasa tidak hanya sebagai suatu bidang kajian, melainkan sebagai faktor sentral dalam perkembangan intelektual, sosial, dan emosional peserta didik. Oleh karena itu penguasaan Bahasa Arab menjadi persyaratan penting bagi keberhasilan individu dalam menjawab tantangan zaman di era globalisasi. Hal ini bertujuan agar peserta didik dapat merespon secara proaktif berbagai perkembangan informasi, ilmu pengetahuan, dan teknologi.

Melalui pembelajaran Bahasa Arab dapat dikembangan keterampilan peserta didik dalam berkomunikasi lisan dan tulisan untuk memahami dan menyampaikan informasi, pikiran dan perasaan. Materi pembelajaran Bahasa Arab diperlukan untuk pengembangan diri peserta didik agar mereka dapat tumbuh dan berkembang menjadi warga negara yang cerdas, terampil, dan berkepribadian serta dapat mengembangkan ilmu pengetahuan, teknologi, budaya dan siap mengambil bagian dalam pembangunan nasional.

Berbagai macam cara telah dilakukan oleh Pemerintah Indonesia dalam meningkatkan mutu pendidikan dengan mengeluarkan berbagai kebijakan kependidikan, secara khusus yang berkaitan dengan pendidikan tinggi. Berbagai kebijakan kependidikan tersebut dituangkan dalam beberapa peraturan antara lain: a) Undang-undang No. 12 Tahun 2012 tentang Pendidikan Tinggi, b) Peraturan Presiden No. 8 Tahun 2012 tentang Kerangka Kualifikasi Nasional Indonesia (KKNI), c) Permendikbud No.73 Tahun 2013 tentang Penerapan KKNI di Perguruan Tinggi,d) Peraturan Pemerintah No. 4 Tahun 2014 tentang Penyelenggaraan Pendidikan Tinggi dan Pengelolaan Perguruan Tinggi, dan e) Peraturan Menteri Pendidikan dan Kebudayaan Nomor 49 Tahun 2014 tentang Standar Nasional Pendididikan Tinggi (SNPT) yang diperbarui dengan Peraturan Menteri Ristekdikti Nomor 44 Tahun 2015.

UU RI Nomor 12 Tahun 2012 tentang SNPT, Pasal 35 ayat 2 mengamanatkan agar kurikulum pendidikan tinggi (KPT) dikembangkan oleh setiap perguruan tinggi dengan mengacu kepada SNPT untuk setiap Program Studi yang mencakup pengembangan kecerdasan intelektual, akhlak mulia, dan keterampilan. Sugiharto (2013 dan 2014) mengemukakan empat tahap penyusunan KPT berdasarkan KKNI 
dan SNPT 2015 melalui empat tahap, yaitu (1) menentukan Profil Lulusan dan Capaian Pembelajaran (CP), (2) memilih dan merangkai bahan kajian, (3) menyusun mata kuliah, struktur Kurikulum, dan menentukan SKS, dan (4) menyusun rencana pembelajaran.

Pada pasal 29 ayat 2 KKNI dinyatakan bahwa KKNI menjadi acuan pokok dalam penetapan kompetensi lulusan pendidikan, baik pendidikan akademik, pendidikan vokasi, maupun profesi. Dalam hal ini, kualifikasi manusia Indonesia dijenjangkan menjadi sembilan jenjang. Pada permenristekdikti no 44 tahun 2015 pasal 5 ayat 1 bahwa standar kompetensi lulusan merupakan kriteria minimal tentang kualifikasi kemampuan lulusan yang mencakup sikap, pengetahuan, danketerampilanyang dinyatakan dalam rumusan capaian pembelajaran lulusan, selanjutnya menjadi acuan dalam mengidentifikasi bahan kajian dan menentukan matakuliah serta bobot sks. ${ }^{1}$

Program Studi Pendidikan Bahasa Arab Fakultas Tarbiyah dan Keguruan UIN Sunan Ampel Surabaya saat ini telah melakukan penyesuaian kurikulum dari Kurikulum Berbasis Kompetensi (KBK) menjadi kurikulum berdasarkan KKNI dan Standar Nasional Perguruan Tinggi (SNPT) 2014 dan sesuai dengan Permenristek Dikti no 44 tahun 2015 tentang SNPT sebagai Kurikulum Pendidikan Tinggi (KPT) yang difokuskan untuk optimalisasi pengembangan proses pembelajaran dan sistem informasi melalui aktivitas penguatan capaian pembelajaran dan daya saing lulusan, yang meliputi peningkatan kualitas practical skills, peningkatan kualitas soft skills, peningkatan efektivitas pembelajaran dengan model Student Centered Learning (SCL) dan efisiensi penyusunan tugas akhir, sehingga lulusan Program Studi Pendidikan Bahasa Arab memiliki profil lulusan yang memiliki daya saing di dunia kerja.

Salah satu diskripsi profil lulusan Program Studi Pendidikan Bahasa Arab Fakultas Tarbiyah dan Keguruan UIN Sunan Ampel Surabaya adalah mampu menjadi Sarjana pendidikan yang memiliki kemampuan kerja, penguasaan pengetahuan, kemampuan manajerial dan tanggung jawab sebagai pendidik dalam bidang mata pelajaran Bahasa Arab pada sekolah/madrasah ( SD/MI, SMP/MTs, SMA/MA/SMK/MAK) yang berkepribadian baik, berpengetahuan luas dan

${ }^{1}$ Republik Indonesia, Peraturan Menteri Ristekdikti Nomor 44 Tahun 2015 tentang Standar Nasional Pendididikan Tinggi (SNPT) 
mutakhir dibidangnya serta mampu melaksanakan tugas dan bertanggung jawab berlandaskan ajaran dan etika keislaman, keilmuan dan keahlian serta dapat menyebarluaskan nilai-nilai IPTEK . ${ }^{2}$

Selain itu, Era modern ini diidentikkan dengan masyarakat digital. Setiap aktifitas manusia akan digerakkan melalui serangkaian teknologi digital karena teknologi menjanjikan perubahan, kemajuan, kemudahan, peningkatan produktifitas, ketepatan dan kecepatan serta popularitas. ${ }^{3}$ Sedang kebanyakan referensi materi bahasa Arab yang ada saat ini masih sangat jarang yang berbasis teknologi atau masih bersifat buku ajar cetak serta belum bersifat interaktif .

Berdasarkan uraian di atas dapat dipahami bahwa masalah penting yang dihadapi dosen dalam pembelajaran Bahasa Arab adalah pembelajaran dengan teknologi atau melalui multimedia, oleh karena itu kami ingin meneliti hal tersebut di atas dengan tema "Pendekatan Whole Languagemelalui Multi Media Dalam Peningkatan Keterampilan Bahasa Arab Bagi Mahasiswa Prodi Pendidikan Bahasa Arab, Fakultas Tarbiyah dan Keguruan, UIN Sunan Ampel Surabaya.

\section{Landasan Teori tentang Pendekatan Whole Language}

Pandangan bahasa holistik atau dikenal dengan istilah whole language memperlakukan bahasa sebagai sesuatu yang bulat dan utuh. Pada hakikatnya "whole language merupakan falsafah pandangan atau keyakinan tentang hakikat belajar dan bagaimana anak belajar secara optimal"4

Whole language adalah satu pendekatan pengajaran. bahasa yang menyajikan bahasa secara utuh, tidak terpisah-pisah. Para ahli whole language berkeyakinan bahwa bahasa akan satu kesatuan (whole) yang tidak dapat dipisahpisahkan. Oleh itu pengajaran keterampilan berbahasa dan komponen bahasa seperti tata bahasa kosakata disajikan secara utuh bermakna dan dalam situasi nyata atau autentik, dalam pengajaran tentang penggunaan tanda baca seperti koma,

2 Faklultas Tarbiyah, Dokumen kurikulum KKNI 2016 Prodi Pendidikan Bahasa Arab, Fakultas Tarbiyah dan Keguruan, UIN Sunan Ampel Surabaya

3 Nanang Martono, Sosiologi Perubahan Sosial (Raja Grafindo Persada: Jakarta), 217-224

4 Sabarti Akhadiah 1991,. 4 
semi-kolon, dan kolonnya diajarkan sehubungan dengan pelajaran menulis. Jangan mengajarkan tanda baca tersebut hanya karena materi itu tertera dalam kurikulum.

Whole language mengandung konsepsi bahwa bahasa merupakan gejala plural yang memiliki keutuhan. Sebab, sebagai bahan pembelajaran, bahasa tidak dapat disikapi sebagai gejala yang tersegmentasikan secara artifisial, melainkan disikapi sebagaimana gejala penggunaannya dalam berbagai peristiwa komunikasi. Sebagai wawasan yang ada dalam konteks pengajaran bahasa, penerapan whole language berimplikasi pada penyikapan bahasa sebagai bahan pembelajaran, bentuk pembelajaran, assessment, dan penilaian. Pada artian luas, "penerapan prinsip tersebut (whole language) berimplikasi pada perencanaan, pelaksanaan, dan penilaian program"5

Pendekatan whole language didasari oleh paham constructivism yang menyatakan bahwa anak/siswa membentuk sendiri pengetahuannya melalui peran aktifnya dalam pembelajaran secara utuh (whole) dan terpadu (integrated). Anak termotivasi belajar jika mereka melihat bahwa yang dipelajarinya itu diperlukan oleh mereka.orang dewasa, dalam hal ini guru, berkewajiban untuk menyediakan lingkungan yang menunjang untuk siswa agar mereka dapat belajar dengan baik. Fungsi guru dalam kelas whole language berubah dari desiminator informasi menjadi fasilitator.

Menurut Routman (1991) dan Froese (1991) ada delapan komponen whole language yaitu reading aloud, journal writing, sustained silent reading, shared reading, guided reading, guided writing, independent reading, dan independent writing. Namun sesuai dengan definisi whole language yaitu pembelajaran bahasa yang disajikan secara utuh dan tidak terpisah-pisah, maka dalam menerapkan setiap komponen whole language di kelas harus pula melibatkan semua keterampilan dan unsur bahasa dalam kegiatan pembelajaran.

Imam Syafi'ie mengemukakan bahwa:"pendekatan integratif dalam pengajaran bahasa Indonesia sebagaimana disebutkan dalam Kurikulum Bahasa Indonesia 1994 bersumber dari whole language, yaitu suatu pandangan kebenaran tentang hakikat proses belajar dan bagaimana mendorong proses tersebut agar

5 Aminuddin (2007). Pembelajaran Terpadu Kurikulum 2013. Malang: Makalah Seminar JPBSI.4 
dapat berlangsung secara efektif dan efisien sehingga dapat mencapai tujuan yang telah ditentukan dalam proses belajar mengajar di sekolah secara optimal". ${ }^{6}$

Pada pengertian ini, whole language dapat dipandang sebagai pendekatan dalam proses belajar mengajar bahasa. Sebagai suatu pendekatan, whole language berdasar pada sejumlah asumsi dari psikolinguistik, sosiolinguistik, psikologi perkembangan anak, teor belajar bahasa, dan pedagogi.

Goodman menyatakan "whole language adalah pendekatan pembelajaran bahasa yang menyajikan bahasa secara utuh, tidak terpisah-pisah"7. Hal ini dipertegas oleh Mary Lynn Redmond yang menyatakan: "the whole language approach provides a learning environment in which the student participates in meaningful language experiences. Through the process of constructing language for communication purposes, the student develops the ability to listen, speak, read, and write in a natural manner".8

Artinya, pendekatan whole language membutuhkan lingkungan pembelajaran yang mana siswa berpartisipasi dalam menyusun bahasa untuk berkomunikasi untuk maksud dan tujuan-tujuan tertentu. Pada pendekatan ini siswa memgembangkan kemampuan mendengar, berbicara, membaca, dan menulis dengan cara alami.

Froese menambahkan bahwa "pemakaian pendekatan whole language menekankan pada kebebasan guru dalam pembelajaran bahasa"9. Guru akan mudah menggunakan pendekatan whole language dalam pembelajaran bahasa, apabila bahasa yang diajarkan digunakan dalam aktivitas sehari-hari sehingga komponen bahasa tersebut menjadi berarti.

6 Syafi'ie, I. (2007). Pendekatan Whole Language dalam Pembelajaran Bahasa. [Online]. Diakses dari: http://journal.um.ac.id/index.php/bahasaseni/articel/view/2445. 12

7 Santosa, P. (2008). Materi dan Pembelajaran Bahasa Indonesia SD. Jakarta: Universitas Terbuka.23

8 Santosa, P. (2008). Materi dan Pembelajaran Bahasa Indonesia SD. Jakarta: Universitas Terbuka. 428

9 Santosa, P. (2008). Materi dan Pembelajaran Bahasa Indonesia SD. Jakarta: Universitas Terbuka.2 


\section{METODE PENELITIAN}

Penelitian ini menggunakan jenis metode penelitian, yaitu metode kuantitatif. ${ }^{10}$ Metode kuantitatif digunakan peneliti untuk mengetahui keefektifan implementasi pembelajaran dengan pendekatan whole language melalui Multi Media.

Analisis yang digunakan dalam penelitian ini menggunakan analisa metode eksperimen quasi (pre-test - post-test with control group design) ${ }^{11}$ dan pendekatan kuantitatif untuk menganalisa kevalidan dan keefektifannya. Untuk membandingkan hasil antara pres-test dan post-test, peneliti menggunakan rumus analisis uji-t sampel berpasangan (paired samples t-test) dan analisis yang akan dilakukan menggunakan software minitab.16.

\section{HASIL PENELITIAN DAN PEMBAHASAN}

Dalam implementasi pembelajaran dengan pendekatan whole language melalui Multi Media dalam peningkatan keterampilan Bahasa Arab bagi mahasiswa prodi pendidikan Bahasa Arab, Fakultas Tarbiyah dan Keguruan, UIN Sunan Ampel Surabaya, peneliti mengimplementasikan pada kelas D sebagai kelas eksperimen pada mata kuliah Istima' Wa Kalam lil Mubtadi'In dengan hasil sebagai berikut:

Dari data hasil pre-test dan post-test, selanjutnya dianalisis melalui uji $\mathrm{t}$ sampel berpasangan (paired sampel test). Uji ini dilakukan untuk mengetahui adanya pengaruh atau tidaknya suatu perlakuan yang diberikan pada kelompok eksperimen penelitian. Hal yang menjadi indikator ada tidaknya pengaruh pada efektivitas belajar siswa adalah bila terjadi perbedaan antara hasil belajar mahasiswa antara sebelum dan sesudah mendapat atau menggunakan bahan ajar yang dikembangkan.

Berdasarkan tabel di atas, dicari apakah bahan ajar yang dikembangkan efektif bagi mahasiswa dalam mempelajari Bahasa Arab atau tidak. Langkahlangkahnya adalah sebagai berikut:

Langkah 1. Membuat Ha dan Ho dalam bentuk kalimat

${ }^{10}$ Sugiono, Metode Penelitian Kombinasi (Mixed Method) (Bandung: Alfabeta, 2013), hlm. 404.

11 Sugiono, ibid. 
Ho : Tidak terdapat perbedaan yang signifikan pada hasil belajar mahasiswa Bahasa Arab sebelum dan sesudah menggunakan pendekatan whole language melalui Multi Media.

Ha : Terdapat perbedaan yang signifikan pada hasil belajar mahasiswa

Bahasa Arab sebelum dan sesudah menggunakan bahan pendekatan whole language melalui Multi Media.

Langkah 2. Mencari nilai t hitung

Adapun hasil perhitungan paired t-test: pre-test, post-test adalah menggunakan Minitab 16 yang hasilnya disajikan dalam bentuk tabel sebagai berikut:

\section{Tabel 1}

Paired T for Pre-Test - Post-Test

\begin{tabular}{|c|c|c|c|c|}
\hline & $\mathrm{N}$ & Mean & $\begin{array}{c}\text { Standar } \\
\text { Deviasi }\end{array}$ & $\begin{array}{c}\text { Stnandar } \\
\text { Eror Mean }\end{array}$ \\
\hline Pre-Test & 21 & 72.86 & 11.02 & 2.40 \\
\hline Post-Test & 21 & 90.00 & 7.07 & 1.54 \\
\hline Difference & 21 & -17.14 & 7.17 & 1.56 \\
\hline
\end{tabular}

\section{Histogram of Differences}

95\% CI for mean difference: $(-20.41,-13.88)$

$\mathrm{T}$-Test of mean difference $=0.05(\mathrm{vs}$ not $=0.05): \mathrm{T}-$ Value $=-10.99 \mathrm{P}-$ Value $=0.000$

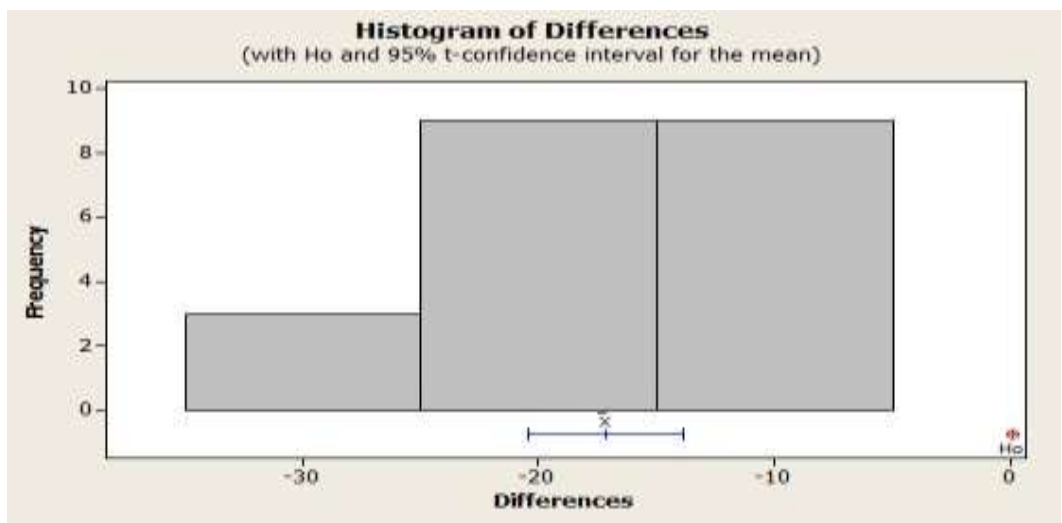


Berdasarkan hasil perhitungan yang dilakukan dengan menggunakan aplikasi Minitab 16 dapat diketahui bahwa besarnya nilai t-hitung dari tabel pre-test dan post-test adalah sebesar 10.99 .

Langkah 3. Menentukan kaidah pengujian

a. Jika nilai $t_{\text {hitung }}>\mathrm{t}_{\text {tabel }}$ maka signifikan, artinya $\mathrm{H}_{0}$ ditolak dan Ha diterima.

b. Jika nilai $t_{\text {hitung }}<t_{\text {tabel }}$ maka signifikan, artinya $\mathrm{H}_{0}$ diterima dan Ha ditolak.

$\mathrm{T}_{\text {tabel }}=\mathrm{t}_{\text {tabel }}: \mathrm{db}$

$\mathrm{Db}=\mathrm{n}-1$

$\mathrm{Db}=21-1$

$\mathrm{Db}=20$

$\mathrm{t}_{\text {tabel }}=\mathrm{t}_{0,05}: 20=1.725$

Jadi $t_{\text {hitung }}(10.99)>t_{\text {tabel }}(1.725)$, sehingga Ha diterima dan $\mathrm{H}_{0}$ ditolak.

Langkah 4. Kesimpulan

Ho : Tidak terdapat perbedaan yang signifikan pada hasil belajar mahasiswa

Bahasa Arab sebelum dan sesudah menggunakan pendekatan whole language melalui Multi Media.

Ha : Terdapat perbedaan yang signifikan pada hasil belajar mahasiswa

Bahasa Arab sebelum dan sesudah menggunakan pendekatan whole language melalui Multi Media.

Jadi, terdapat perbedaan yang signifikan pada hasil belajar mahasiswa Bahasa Arab sebelum dan sesudah menggunakan pendekatan whole language melalui Multi Media.

Selain mengimplementasi pembelajaran dengan pendekatan whole language melalui Multi Media dalam peningkatan keterampilan Bahasa Arab bagi mahasiswa prodi pendidikan Bahasa Arab, Fakultas Tarbiyah dan Keguruan, UIN Sunan Ampel Surabaya pada kelas D sebagi kelas eksperimen, peneliti juga mengimplementasikan pembelajaran dengan tidak mengunakan pendekatan whole language melalui Multi Media sebagai kelas pembanding pada kelas B.

Dari data hasil pre-test dan post-test, selanjutnya dianalisis melalui ujji $\mathrm{t}$ sampel berpasangan (paired sampel test). Pengujian ini dilakukan sebagaimana dengan tujuan tersebut di atas pada kelas eksperimen dan juga dengan menggunakan langkah-langkah yang sama tersebut di atas. 
Langkah 1. Membuat Ha dan Ho dalam bentuk kalimat

Ho : Tidak terdapat perbedaan yang signifikan pada hasil belajar mahasiswa Bahasa Arab sebelum dan sesudah menggunakan pendekatan whole language melalui Multi Media.

Ha : Terdapat perbedaan yang signifikan pada hasil belajar mahasiswa Bahasa Arab sebelum dan sesudah menggunakan pendekatan whole language melalui Multi Media.

Langkah 2. Mencari nilai t hitung

Adapun hasil perhitungan paired t-test: pre-test, post-test adalah menggunakan Minitab 16 yang hasilnya disajikan dalam bentuk tabel sebagai berikut:

Tabel 2

Paired T for Pre-Test - Post-Test

\begin{tabular}{|c|c|c|c|c|}
\hline & $\mathrm{N}$ & Mean & $\begin{array}{c}\text { Standar } \\
\text { Deviasi }\end{array}$ & $\begin{array}{c}\text { Stnandar } \\
\text { Eror Mean }\end{array}$ \\
\hline Pre-Test & 21 & 76.67 & 6.58 & 1.44 \\
\hline Post-Test & 21 & 82.86 & 7.17 & 1.56 \\
\hline Difference & 21 & -6.19 & 4.98 & 1.09 \\
\hline
\end{tabular}

95\% CI for mean difference: $(-8.46,-3.93)$

$\mathrm{T}$-Test of mean difference $=0.05(\mathrm{vs}$ not $=0.05): \mathrm{T}-$ Value $=-5.75$

P-Value $=0.000$

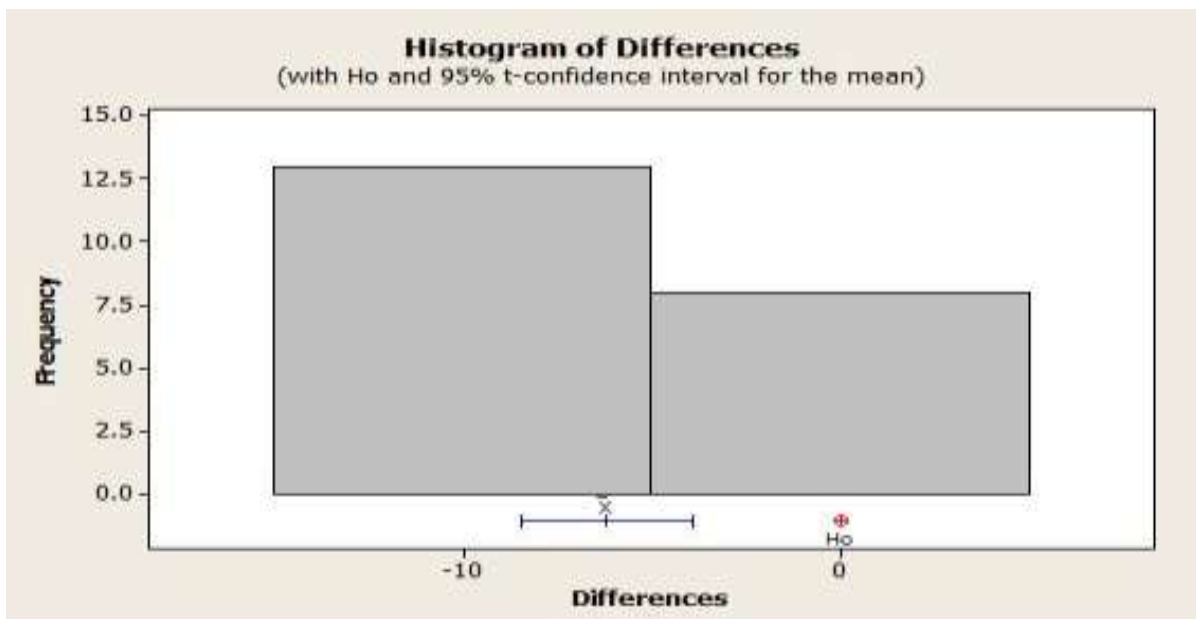

Gambar 2 
Berdasarkan hasil perhitungan yang dilakukan dengan menggunakan aplikasi Minitab 16 dapat diketahui bahwa besarnya nilai t-hitung dari tabel pre-test dan post-test adalah sebesar 5.75 .

Langkah 3. Menentukan kaidah pengujian

a. Jika nilai $t_{\text {hitung }}>\mathrm{t}_{\text {tabel }}$ maka signifikan, artinya $\mathrm{H}_{0}$ ditolak dan Ha diterima.

b. Jika nilai $t_{\text {hitung }}<\mathrm{t}_{\text {tabel }}$ maka signifikan, artinya $\mathrm{H}_{0}$ diterima dan Ha ditolak.

$\mathrm{T}_{\text {tabel }}=\mathrm{t}_{\text {tabel }}: \mathrm{db}$

$\mathrm{Db}=\mathrm{n}-1$

$\mathrm{Db}=21-1$

$\mathrm{Db}=20$

$\mathrm{t}_{\text {tabel }}=\mathrm{t}_{0,05}: 20=1.725$

Jadi $t_{\text {hitung }}(5.75)>t_{\text {tabel }}(1.725)$, sehingga Ha diterima dan $\mathrm{H}_{0}$ ditolak.

Langkah 4. Kesimpulan

Ho : Tidak terdapat perbedaan yang signifikan pada hasil belajar mahasiswa

Bahasa Arab sebelum dan sesudah menggunakan pendekatan whole language melalui Multi Media.

Ha : Terdapat perbedaan yang signifikan pada hasil belajar mahasiswa

Bahasa Arab sebelum dan sesudah menggunakan pendekatan whole language melalui Multi Media.

Jadi, terdapat perbedaan yang signifikan pada hasil belajar mahasiswa Bahasa Arab sebelum dan sesudah menggunakan pendekatan whole language melalui Multi Media.

\section{KESIMPULAN}

Dalam mengimplementasi pembelajaran dengan pendekatan whole language melalui Multi Media dalam peningkatan keterampilan Bahasa Arab bagi mahasiswa prodi pendidikan Bahasa Arab, Fakultas Tarbiyah dan Keguruan, UIN Sunan Ampel Surabaya pada kelas D sebagai kelas eksperimen, peneliti juga mengimplementasikan pembelajaran dengan tidak mengunakan pendekatan whole language melalui Multi Media sebagai kelas pembanding yaitu pada kelas B. 
Berdasarkan hasil perhitungan yang dilakukan dengan menggunakan aplikasi Minitab 16 dapat diketahui bahwa besarnya nilai t-hitung dari tabel pre-test dan post-test pada kelas eksperimen atau kelas D adalah sebesar 10.99.

Adapun hasil perhitungan yang dilakukan dengan menggunakan aplikasi Minitab 16 dapat diketahui bahwa besarnya nilai t-hitung dari tabel pre-test dan post-test pada kelas control adalah sebesar 5.75 .

Dengan demikian terdapat perbedaan yang signifikan pada hasil belajar mahasiswa Bahasa Arab sebelum dan sesudah menggunakan pendekatan whole language melalui Multi Media dan juga terdapat perbedaan yang signifikan pada hasil belajar mahasiswa Bahasa Arab antar kelas experiment dengan kelas control yaitu nilai t-hitung dari tabel pre-test dan post-test pada kelas eksperimen atau kelas D adalah sebesar 10.99 dan nilai t-hitung dari tabel pre-test dan post-test pada kelas control adalah sebesar 5.75

\section{DAFTAR PUSTAKA}

Aminuddin (2007). Pembelajaran Terpadu Kurikulum 2013. Malang: Makalah Seminar JPBSI.4

Faklultas Tarbiyah, Dokumen kurikulum KKNI 2016 Prodi Pendidikan Bahasa Arab,

Fakultas Tarbiyah dan Keguruan, UIN Sunan Ampel Surabaya .

Martono, Nanang. Sosiologi Perubahan Sosial (Raja Grafindo Persada: Jakarta).

Republik Indonesia, Peraturan Menteri Ristekdikti Nomor 44 Tahun 2015 tentang Standar Nasional Pendididikan Tinggi (SNPT)

Santosa, P. (2008). Materi dan Pembelajaran Bahasa Indonesia SD. Jakarta: Universitas Terbuka

Sugiono, Metode penelitian Kombinasi (Mixed Method). Bandung: Alfabeta, 2013.

Syafi'ie, I. (2007). Pendekatan Whole Language dalam Pembelajaran Bahasa. [Online]. Diakses dari: http://journal.um.ac.id/index.php/bahasaseni/articel/view/2445. 